\title{
Spectrum splitting for efficient utilization of solar radiation: a novel photovoltaic-thermoelectric power generation system
}

\author{
Esam Elsarrag ${ }^{1 *} \mathbb{D}$, Hans Pernau², Jana Heuer², Nibul Roshan ${ }^{1}$, Yousef Alhorr ${ }^{1}$ and Kilian Bartholomé2
}

\begin{abstract}
Standard photovoltaic solar cells (PV cells) use only about half of the light spectrum provided by the sun. The infrared part is not utilized to produce electricity. Instead, the infrared light heats up the PV cells and thereby decreases the efficiency of the cell. Within this research project, a hybrid solar cell made of a standard PV cell and a thermally driven thermoelectric generator (TEG) is being developed. The light of the sun splits at about $800 \mathrm{~nm}$. The visible and ultraviolet part is transferred to the PV cell; the infrared part illuminates the thermal TEG cell. With the hybrid solar cell, the full solar spectrum is exploited. In this paper, theoretical and experimental results for improving the performance of thermoelectric elements coupled with photovoltaic modules have been presented. The proposed concepts and the experimental results have provided a key input to develop a large scale of a hybrid PV-TE system.
\end{abstract}

Keywords: Photovoltaic, Thermoelectric, Hybrid system, Renewable energy, Solar energy

\section{Background}

The basic idea for a combined PV and thermoelectric solar cell has been published in 2008 (Tritt et al. 2008). The history of thermoelectricity began in 1823 when Seebeck made his experiments about the conversion of a temperature gradient into an electrical current (Seebeck 1895). Especially within the last decade research on thermoelectric materials and systems has been intensified due to the awareness of the need to increase the efficiency of energy consumption. Thermoelectric devices can convert waste heat directly into electrical energy. Many efforts in this field have been made to implement thermoelectric generators (TEG) in automotive applications. The conversion efficiency of TE generators depends on the available temperatures and the material properties, namely the dimensionless figure of merit ZT:

$$
\mathrm{ZT}=\frac{\alpha^{2} \sigma}{\lambda} T
$$

\footnotetext{
*Correspondence: e.elsarrag@gord.qa

${ }^{1}$ Gulf Organisation for Research and Development, QSTP, Doha, Qatar

Full list of author information is available at the end of the article
}

$T$ is the absolute temperature, $\alpha$ the Seebeck coefficient, $\sigma$ the electrical conductivity and $\lambda$ the thermal conductivity. Based on this value the conversion efficiency of the thermoelectric material using the temperature gradient between the hot side temperature $T_{\mathrm{h}}$ and cold side temperature $T_{\mathrm{c}}$ can be calculated as:

$$
\eta_{\mathrm{TE}}=\eta_{\mathrm{c}}\left(\frac{\sqrt{1+\mathrm{ZT}}-1}{\sqrt{1+\mathrm{ZT}}+\frac{T_{c}}{T_{h}}}\right)
$$

where $\eta_{\mathrm{c}}$ is the Carnot efficiency. The higher the $\mathrm{ZT}$ value of the material the closer is the efficiency to the Carnot limit. Modern thermoelectric materials reach ZT values larger than 1 and with efficiencies more than $4 \%$ (Tritt et al. 2008). Using the technique of thermoelectric generators, to convert the infrared part of the sun spectrum into electrical energy, we could increase the overall performance of a combined PV and TE solar cell by approximately $10 \%$ of the PV, thereby achieving around $20 \%$ efficiency with the combined system rather than the $17-18 \%$ efficiency from the PV-only setup.
勿

(c) 2015 Elsarrag et al. This article is distributed under the terms of the Creative Commons Attribution 4.0 International License (http://creativecommons.org/licenses/by/4.0/), which permits unrestricted use, distribution, and reproduction in any medium, provided you give appropriate credit to the original author(s) and the source, provide a link to the Creative Commons license, and indicate if changes were made. 
The basic idea of PV-TE was introduced by Tritt (2008) and Kraemer et al. (2011) who studied the utilization of both ultraviolet (UV) and infrared (IR) parts. Various papers have been published dealing with the combined use of thermoelectric and PV or solar thermal systems. Baranowski et al. (2012) claimed efficiencies of $15.9 \%$ for concentrated solar thermoelectric generators (STEG) by developing a balance model and analyzing the present day materials under ideal conditions. A number of works on the STEG hybrids are based on concentrating solar power on to TEGs. Chávez Urbiola and Vorobiev (2013) designed and tested such a system with co-generation of hot water which was used as the coolant for the TEG hotside and achieving $5 \%$ electrical efficiency. The studies conducted by Eswaramoorthy and Sanmugam (2013) and Kalogirou (2013) on the use of such systems in specific geographic locations gave more insight into the feasibility and possibility of large scale deployment of the systems. Leon et al. (2012) and Lertsatitthanakorn et al. (2013a, 2013b) evaluated the possibilities of concentrated solar power on hybrid systems using different strategies for TEG design and the cooling technique. Lippong et al. (2012) successfully implemented a cooling mechanism for solar TEG hybrid using phase change material and implied the possibility of using it as a sustainable system for independent operation. McEnany et al. (2011) developed an analysis model and denotes that, with the presently available materials and technology, efficiencies of more than $10 \%$ can be achieved using solar TEG hybrid systems by the cascading of TEGs and under high temperature and optical irradiance operation. Meir et al. (2013) suggested controlled shaping of electric potential distribution in the thermoelectric converters for more efficient generation of thermoelectric energy, in theory. Mizoshiri et al. (2012) tested a hybrid system by implementing spectrum splitting on a thin-film TEG and focusing the near infra-red (NIR) radiation onto the TEG while the PV received the rest of the spectrum. The use of thin-film selective absorber coating for TEGs in the performance of hybrid systems was investigated by Ogbonnaya et al. (2013). Van Sark (2011) developed a model to analyse the feasibility of a PV-thermoelectric module in outdoor conditions and provided very optimistic results by considering ideal conditions of operation. Advances in the related fields such as: (1) the development of highperformance spectrally-selective solar absorber based on a yttria-stabilized zirconia cermet with high- temperature stability by Wang et al. (2011), (2) thin-film TEG model by Weinstein et al. (2013) which can be used in place of conventional TEGs with minimal losses, and (3) the multi-hybrid cell by Yang et al. (2013), which can harvest mechanical, solar and thermal energy at the same time, provided strength to the optimistic feasibility predictions of van Sark and Zhang et al. (2013) to come true. One such promising field is the solar spectrum splitting for energy co-generation. Within all these works, the splitting of the solar spectrum was discussed theoretically but not investigated in an extensive practical manner, except for Mizoshiri et al. (2012) who generated an open voltage of $79 \mathrm{mV}$.

This study will investigate the performance of a thermoelectric generator by changing its material constitution and design features. The TEG is anticipated to be integrated with PV modules to form a hybrid photovoltaic-thermoelectric generator and increase the overall conversion efficiency from solar irradiance to electricity.

\section{Methods}

\section{The first system setup}

Figure 1 shows a simplified solar spectrum and the energy fractions which could be used by the PV cell and the TEG. Based on this concept, the first principal design was developed and implemented in a versatile test hybrid cell as shown in Fig. 2. This system consists of $15 \mathrm{~cm} \times 15 \mathrm{~cm}$ monocrystalline PV cell, $1.5 \mathrm{~cm} \times 1.5 \mathrm{~cm}$ TEG [Quickohm Model QC 31-1.0-3.9 M (Quick Cool Shop 2015)] and a beam splitter. For the first test setup, a so called "cold mirror" made by OpticBalzers (Datasheet: Cold Mirror 2015) was used to split the solar radiation. The beam splitter was placed at an angle of $45^{\circ}$ to both the PV and TEG.

The spectral characteristic of this mirror is shown in Fig. 3. As shown in the figure, the cut-off wavelength of

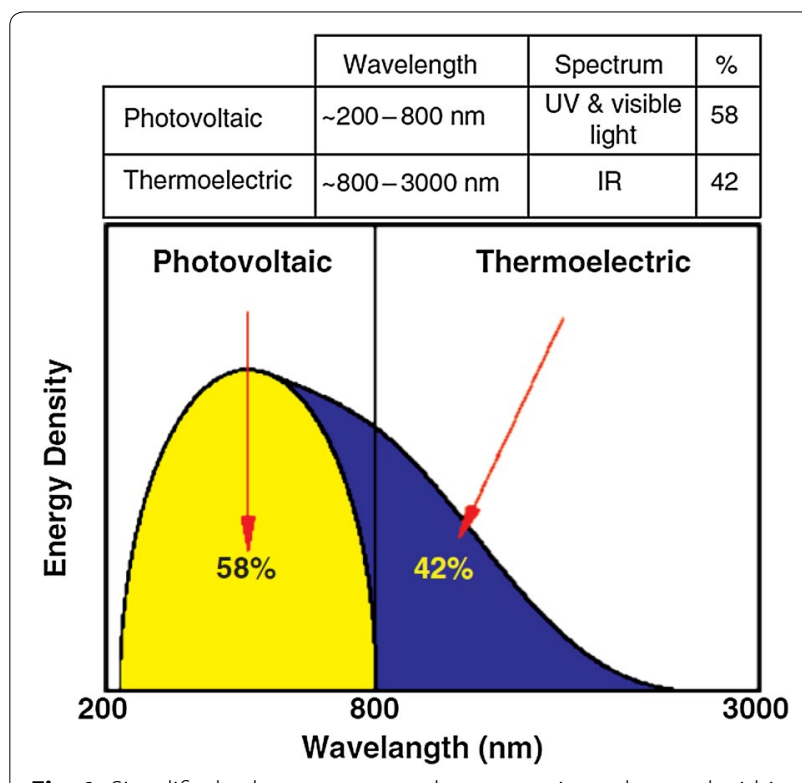

Fig. 1 Simplified solar spectrum and energy ratios to be used within the PV cell and the TEG (Tritt et al. 2008) 


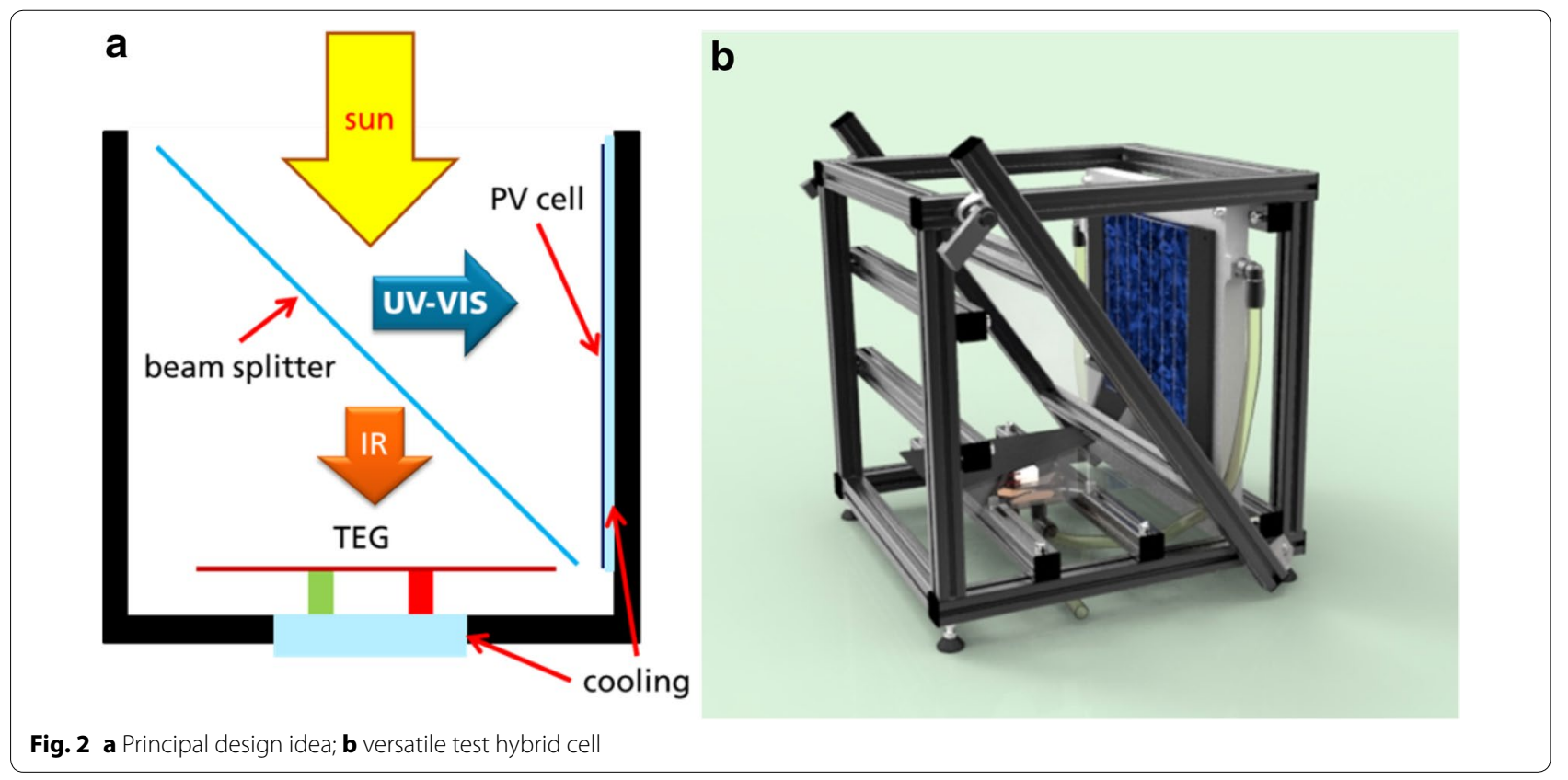

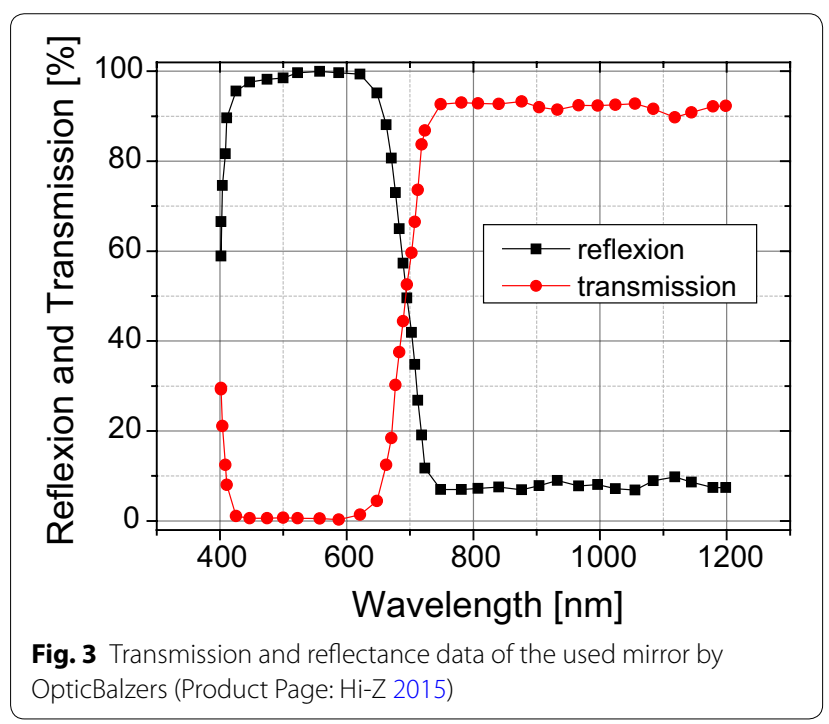

this mirror is $700 \mathrm{~nm}$, a little bit lower than the desired $800 \mathrm{~nm}$, this leads to an approximate 50/50 splitting of the energy in the setup.

The test rig was designed to allow independent movements of the system components. It offers enough space to test different types of PV cells, absorbers and beam splitters. In the test rig both the PV cell and the TEG can be cooled, the input and output temperature of both coolers can be monitored. Both coolers use a liquid cooling media provided by a radiator cooling tower with an estimated cooling power of $1000 \mathrm{~W}$. The lowest possible temperature depends on the surrounding temperature during measurements.
It has to be evaluated within the project if a tailored mirror with $800 \mathrm{~nm}$ or another cut-off wavelength will achieve better performance or not. As the project aims to use commercially available parts to minimize system costs for the final hybrid module, the mirror from OpticBalzers was considered to initiate the tests.

To verify the experimental data presented by Seebeck (1895), FEM simulation with Comsol Multiphysics was performed. The thermal absorber was simulated using the solar radiation tool enclosed in the heat transfer module. Two commercially available absorber materials were chosen for the simulations and lab tests. These

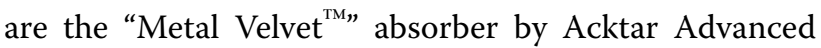

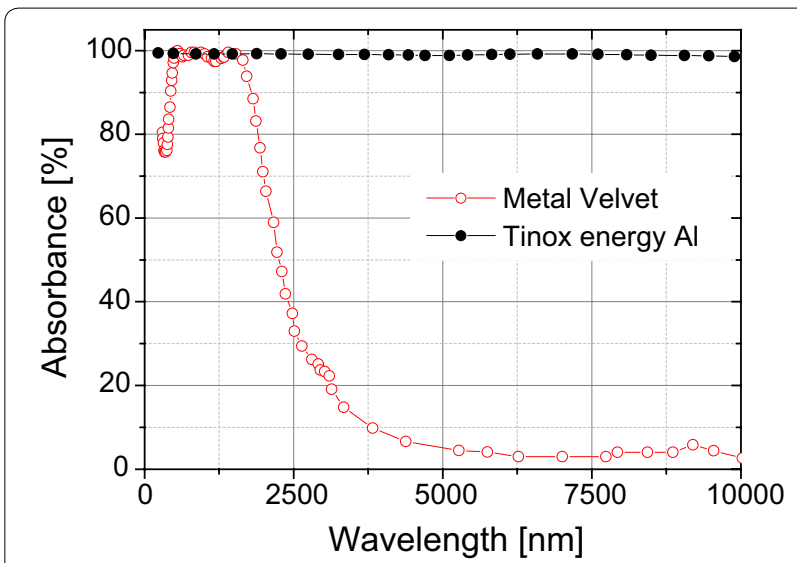

Fig. 4 Absorption data of (black dots) the "Metal Velvet ${ }^{\mathrm{TM}{ }^{\prime \prime}}$ absorber by Acktar Advanced Coatings (Datasheet: Cold Mirror 2015) and (red circles) the "Tinox ${ }^{\circledR}$ energy Al" by Almecosolar (Website 2015) 
Coatings (Website 2015) and the "Tinox ${ }^{\circledR}$ energy Al" by Almecosolar (Datasheet: Solare Absorberbeschichtungen 2015). The absorption data of both absorbers are shown in Fig. 4. The main difference between these two absorbers is the absorbance of IR light above $2.5 \mu \mathrm{m}$. "Metal Velvet $^{\mathrm{TM} \text { " }}$ is black up to very long wavelength as "Tinox ${ }^{\circledR}$ energy Al" is a so-called selective absorber and becomes transparent above $2.5 \mu \mathrm{m}$ that leads to reduced emission losses. That is because the emissivity and the absorbance of an optically dense body are equal. If the absorber is heated by the sun, it will emit black body radiation in the range of about $5-8 \mu \mathrm{m}$ wavelength depending on its temperature. This radiation loss reduces the maximum temperature which can be achieved in the system. The simulation results have shown that the "Metal Velvet ${ }^{\mathrm{TM}}$ " absorber can reach up to $110^{\circ} \mathrm{C}$ but the "Tinox ${ }^{\circledR}$ energy Al" can reach up to $345{ }^{\circ} \mathrm{C}$ in vacuum (the coating was in both cases attached to a $250 \mu \mathrm{m}$ aluminum plate).

In the next simulation step, a TEG and absorber were included in the model with a parameterized footprint area and height. The cold side of the TEG was attached to a $45^{\circ} \mathrm{C}$ surface with a thermal conductivity of $1000 \mathrm{~W} /$ $\mathrm{mK}$. The thermal conductivity between TEG and absorber plate was set to infinite.

Changing the footprint area from $2.5 \times 2.5$ to $50 \times 50 \mathrm{~mm}^{2}$ the achievable hot and cold side temperatures as well as the heat flux through the TEG were simulated. The temperatures and an estimated generator power are plotted in Fig. 5. The conversion efficiency of the TEG was calculated from measured ZT data; together with the simulated heat flux the power was obtained. It can be seen that starting from the side length of around $18 \mathrm{~mm}$ of a square cut TEG; the TEG power output was proportional the temperature difference between the hot side and the cold side surfaces.

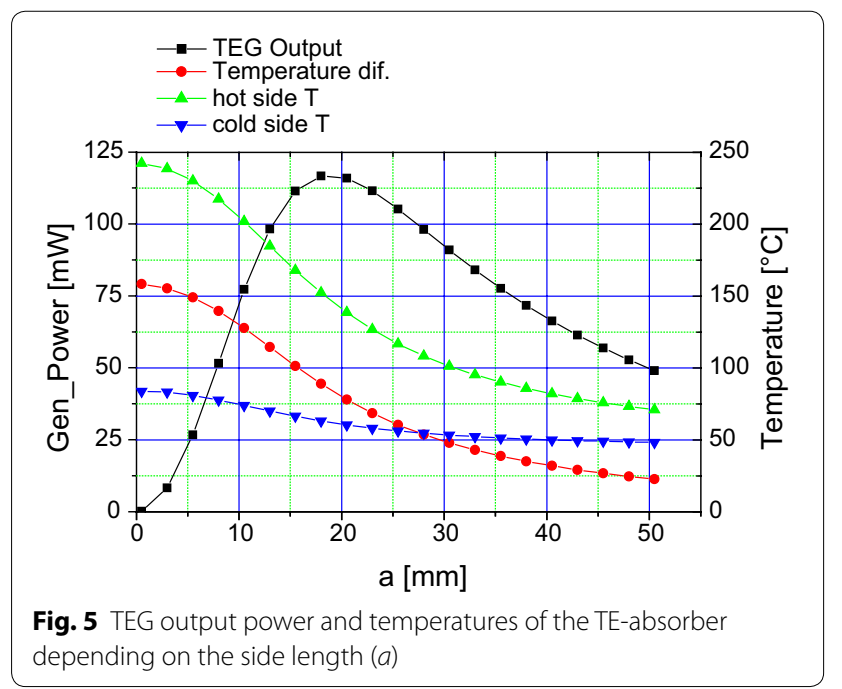

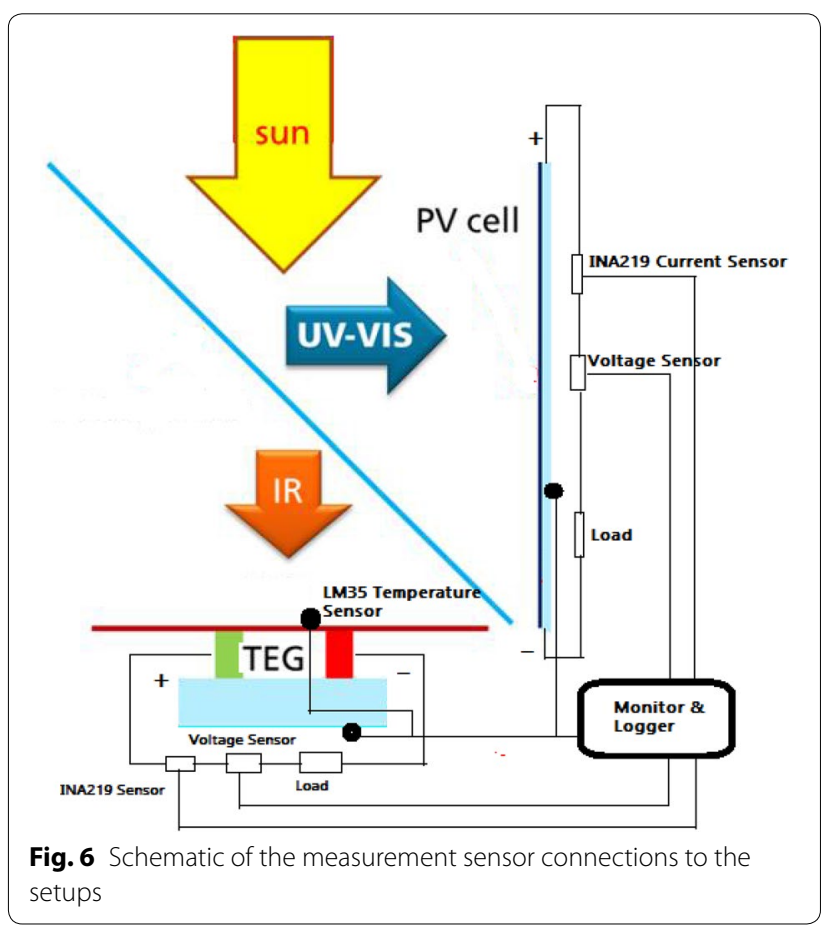

For the next steps, the TEG model will be enhanced using the Comsol models developed by Jägle et al. (2008). Using the material data of the real TEG modules, the real performance of the system can be evaluated with a good accuracy.

\section{The second system setup}

A second set of tests was conducted to compare the performance of the Hybrid PV system with a standard system. The Hybrid system consisted of a small size $(15 \mathrm{~cm}$ $\times 15 \mathrm{~cm})$ monocrystalline, custom made, low power PV Panel and a comparable sized TEG, Model HiZ-2, $(2.9 \times 2.9 \mathrm{~cm})$. The setup makes use of the Bismuth Telluride based 'HZ-2' TEG Model from Hi Z (Product Page: $\mathrm{Hi}-\mathrm{Z}$ 2015) which accommodates 97 thermocouples in $2.9 \mathrm{~cm} \times 2.9 \mathrm{~cm} \times 0.508 \mathrm{~cm}$ and has a conversion efficiency of $4.5 \%$. The TEG typically produces 2.5 Watts at 3.3 volts at Matched Load with a $200{ }^{\circ} \mathrm{C}$ temperature gradient between the surfaces at $30^{\circ} \mathrm{C}$ ambient temperature. The standard system had a similar PV only setup. The testing was conducted in a solar simulator chamber (Model: SEC 1100, Manufacturer: Atlas) [Product Page: Atlas SEC 1100 (2015)].

The test setup was such that, both the benches were tested simultaneously inside the chamber. The Hybrid bench had the light falling on the cold mirror which was at $45^{\circ}$ to the fixed light source to facilitate splitting of the light by the cold mirror (angle of incidence $45^{\circ}$ ). The mirror would split the incident light to the PV and 
TEG surfaces. The absorber surface with the TEG would get the IR radiation passing via the mirror. The PV surface, which is at $45^{\circ}$ to the mirror and hence perpendicular to the light source, gets illuminated with the rest of the wavelength which is reflected by the mirror. The cold side of the TEG was cooled by an Aquaduct 360 Eco Mark II External water cooling tower (2015) and this temperature was dependent on the ambient temperature. The ambient temperature inside the chamber was kept at a constant maximum of $50{ }^{\circ} \mathrm{C}$. The normal test bench had the similar PV facing the light at $45^{\circ}$ and was parallel to the mirror in the Hybrid bench, to make sure that both test setups had the same amount of light incident on them. The measurements were made using a purpose built microcontroller based embedded system using sensors to monitor the current, voltage and temperature levels of the different parts of the setup as shown in Fig. 6. The logging was done in real time high frequency samples and saved to a memory card in CSV format for easy analysis. The sensors used included
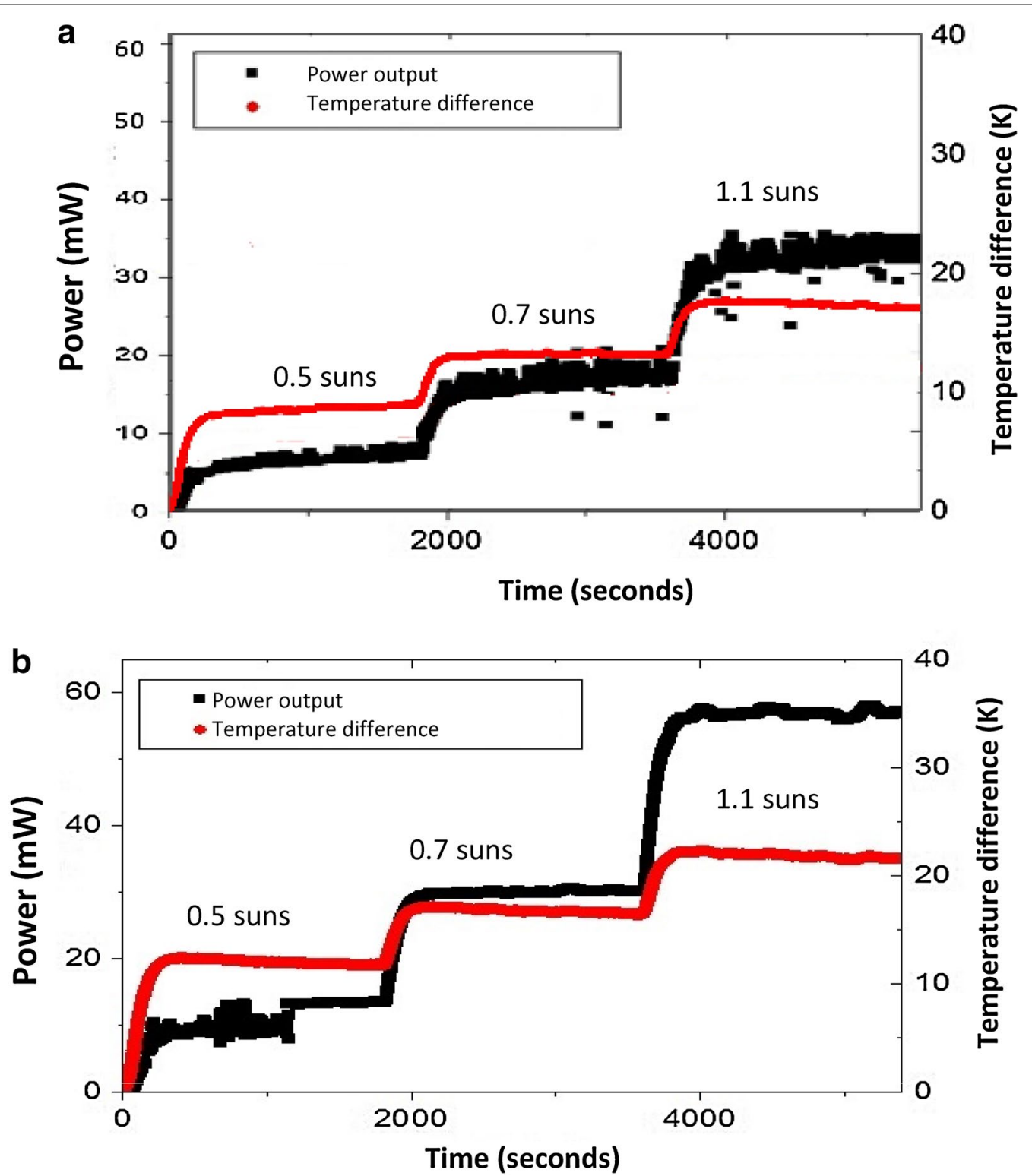

Fig. 7 a Temperature of the absorber made from the "Metal Velvet ${ }^{\mathrm{TM} \text { " }}$ and the cooler plate and the output power of the TEG plotted over the radiation flux of the solar simulator. $\mathbf{b}$ Temperature of the absorber made from the "Tinox ${ }^{\circledR}$ energy Al" and the cooler plate and the output power of the TEG plotted over the radiation flux of the solar simulato 
LM35 precision IC for temperature sensing with a range of $0-100{ }^{\circ} \mathrm{C}$ and an accuracy of $0.25{ }^{\circ} \mathrm{C}$ at high ambient temperatures (Datasheet: LM35 sensor 2015). The PV and TEG currents were measured using INA219 based sensors, with a resolution of $0.8 \mathrm{~mA}$ and a maximum range of \pm 3.2 A measurement (Datasheet: INA219 sensor 2015). A $20 \times 4$ parallel interface graphical LCD provided real time data display for monitoring purposes. The data saving was done via a memory card shield and a DS1307 based Real Time Clock (RTC) module (Datasheet: RTC 2015). The loads used for both PVs were 8 Ohm independent resistive Loads and the TEG having a $1 \mathrm{Ohm}$ resistive Load. The irradiance levels were gradually changed in 8 steps from 300 to $800 \mathrm{~W} / \mathrm{m}^{2}$, which were the available steps in the SEC 1100 Model. The Output of the Normal system provides an output without the sunlight splitting, while the Hybrid System performance is after the sunlight splitting.

\section{Results and discussion}

\section{The first setup results}

To verify the simulation results first laboratory test have been done using the same $15 \times 15 \mathrm{~mm}^{2}$ TEG [Quickohm Model QC 31-1.0-3.9 M ( 2015)] under the absorber plate. Each absorber material is attached to a $250 \mu \mathrm{m}$ Aluminum sheet. These absorber plates are interfaced with the TEG using a very thin layer (less than $1 \mathrm{~mm}$ ) of Arctic Silver 5 thermal conductive paste which a Thermal conductivity of $8.9 \mathrm{~W} / \mathrm{mK}$ (Product Page: Arctic Silver 2015). The measurements are performed in the solar simulator setup. The spectrum shape is similar to the AM1.5 standard and can be adjusted in its flux level from 0.12 to 1.1 suns. The output power of the TEG's is measured via the voltage over a reference resistor of $1 \Omega$. The cold side is cooled using a radiator cool tower system. The temperatures of the cooler plate and the absorber plate are measured with PT100 thin film thermometers. The voltages, as well as the two resistances, are measured with a Keithley 2700/7700 multi-meter. The obtained data are plotted in Fig. 7 over the radiation flux of the solar simulator. Both Fig. 7a, b show that the temperature difference between two surfaces of the absorbers "Metal Velvet ${ }^{\mathrm{TM}}$ " and "Tinox ${ }^{\circledR}$ energy Al". The power output of the TEG(s) is proportional to the level of solar irradiations falling on the absorber's surface.

As revealed in Fig. 4, the absorbance of "Metal Velvet" keeps at $100 \%$ corresponding to any values of wavelength from 0 to $10,000 \mathrm{~nm}$. The maximum temperature difference was around $18 \mathrm{~K}$ under the solar radiation level at 1.1 suns as shown in Fig. 7a. The corresponding power output at 1.1 suns was about $32 \mathrm{~mW}$. However, due to the selective absorbance characteristic of "Tinox ${ }^{\circledR}$ energy $\mathrm{Al}$ ", the absorber greatly reduced the radiation emission heat loss and sustained a higher temperature between the hot and cold surface. As shown in Fig. 7a, b, the power output and the temperature difference between the two sides of "Tinox ${ }^{\circledR}$ energy Al" absorber-TEG assembly were always higher than the "Metal Velvet" ${ }^{\mathrm{TM}}$ " absorber-TEG assembly under different solar irradiation conditions of 500, 700 and $1000 \mathrm{~W} / \mathrm{m}^{2}$.

In order to achieve a higher temperature difference in the TEG, apart from changing the absorbance characteristic, another measure aimed to reduce the convective heat loss on the surface of the absorber by covering the absorber surface with the honeycomb was investigated. The experimental setup with honeycomb cover is shown in Fig. 8. At first, two different material absorbers had been cut into $7.5 \times 7.5 \mathrm{~cm}^{2}$ pieces and had been placed on a thermally insulating Styropor block inside the solar simulator as shown in Fig. 9. The temperature of the absorber was measured with PT 100 sensor glued

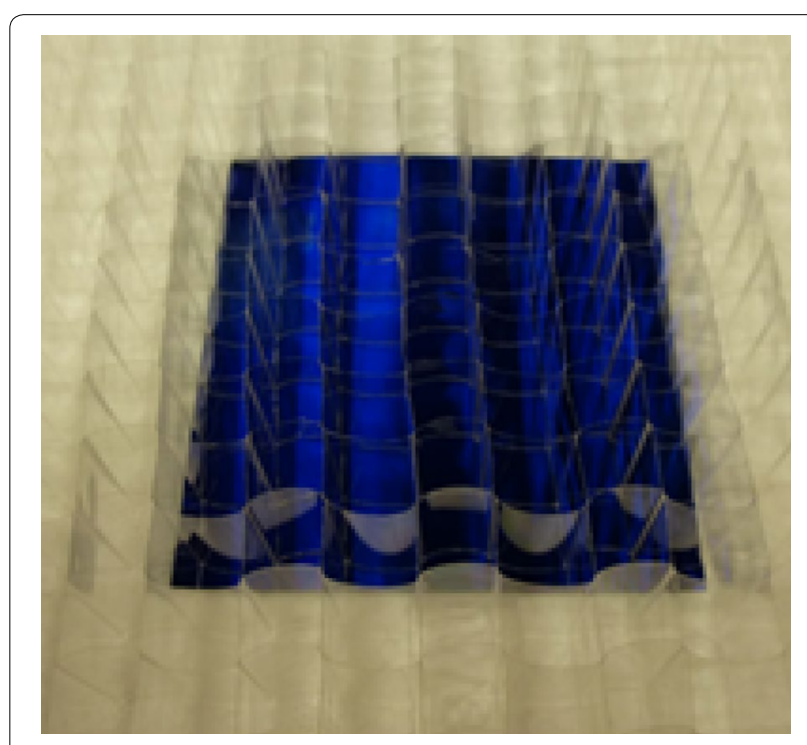

Fig. 8 Honeycomb structure on top of the absorber to reduce convection losses

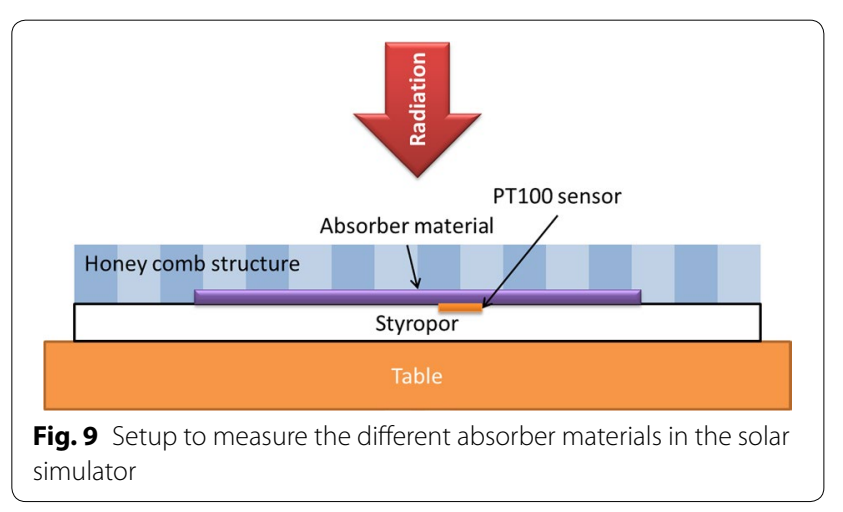




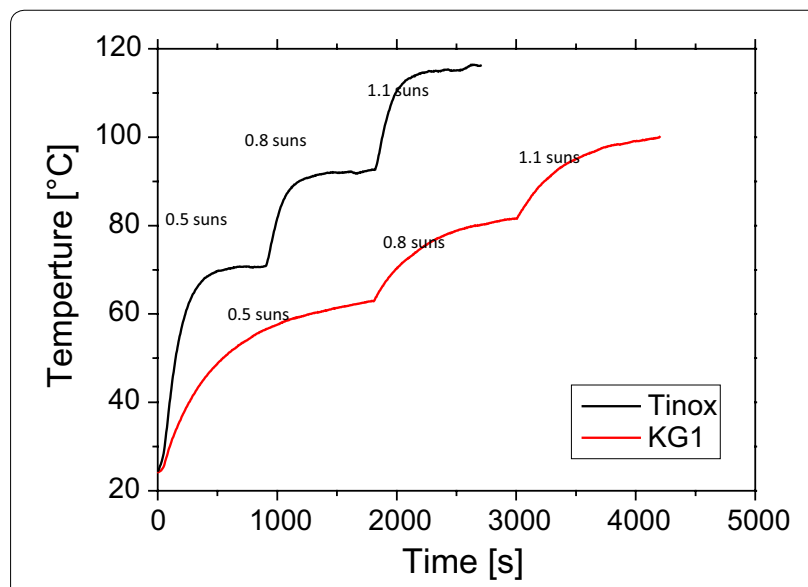

Fig. 10 Temperature of the KG-1 glass (red) and the Tinox absorber (black) as a function of time

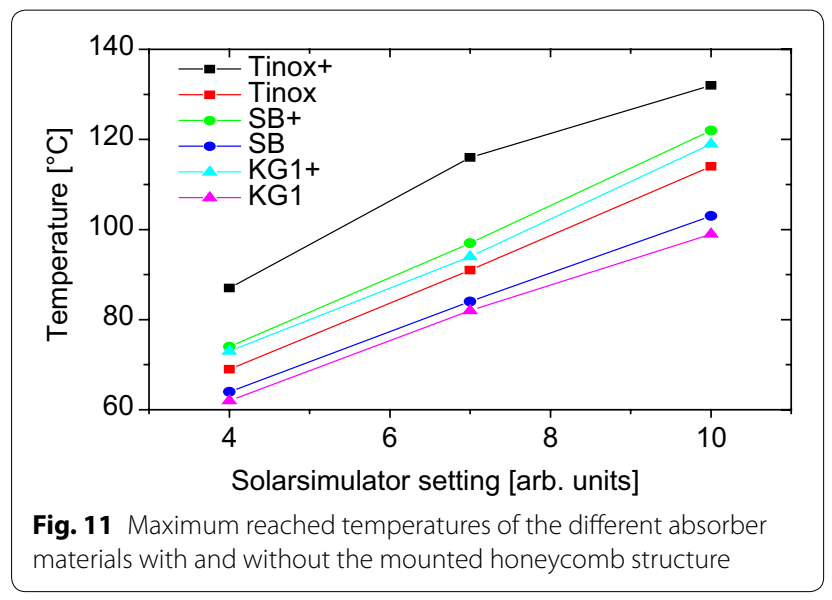

to the backside of the absorber plate covered inside the Styropor block. In the first experiment, the setups were covered with honey-comb. The purpose experiment only intends to compare the performance two different absorber materials.

The two absorbers being compared in this part were "KG-1" and "Tinox". The thickness of the heat absorber glass KG-1 was $3 \mathrm{~mm}$. The thermal mass of "KG-1" is 40 times higher than the non-transparent absorber "Tinox" which was deposited on a $0.2 \mathrm{~mm}$ aluminum foil. Owing to the high thermal mass, the response time to a radiation change of "KG-1" absorber was much higher.

Figure 10 shows the temperature profiles of the "KG-1" absorber and the "Tinox" absorber under the solar irradiation of $0.5,0.8$ and 1.1 suns against time. It is obvious to note that the temperature of the "Tinox" absorber was always much higher than the "KG-1" glass absorber. Because of the high thermal mass, the response time for a radiation change and the maximum temperature reached were low.

Finally, the achieved temperatures with and without the honey-comb structure of three types of absorbers are shown in Fig. 11. The use of the honey-comb-structure leads to an increased temperature as the convective heat loss is reduced. Again, it is clear that minimizing the convective heat loss from the absorber surface enables to maximize the absorber's temperature and potentially increases the electricity generation by the thermoelectric effect.

\section{The second setup results}

The solar simulator was set to provide irradiance between 200 and $800 \mathrm{~W} / \mathrm{m}^{2}$, as shown in Fig. 12. Initially it is aimed to compare only the outputs the Normal (conventional) $\mathrm{PV}$ and the PV with the split mirror using two benches on the same time. It was noted that the PV with the splitted spectrum performed better than the Normal $\mathrm{PV}$ at low irradiance levels up to $700 \mathrm{~W} / \mathrm{m}^{2}$. Beyond this

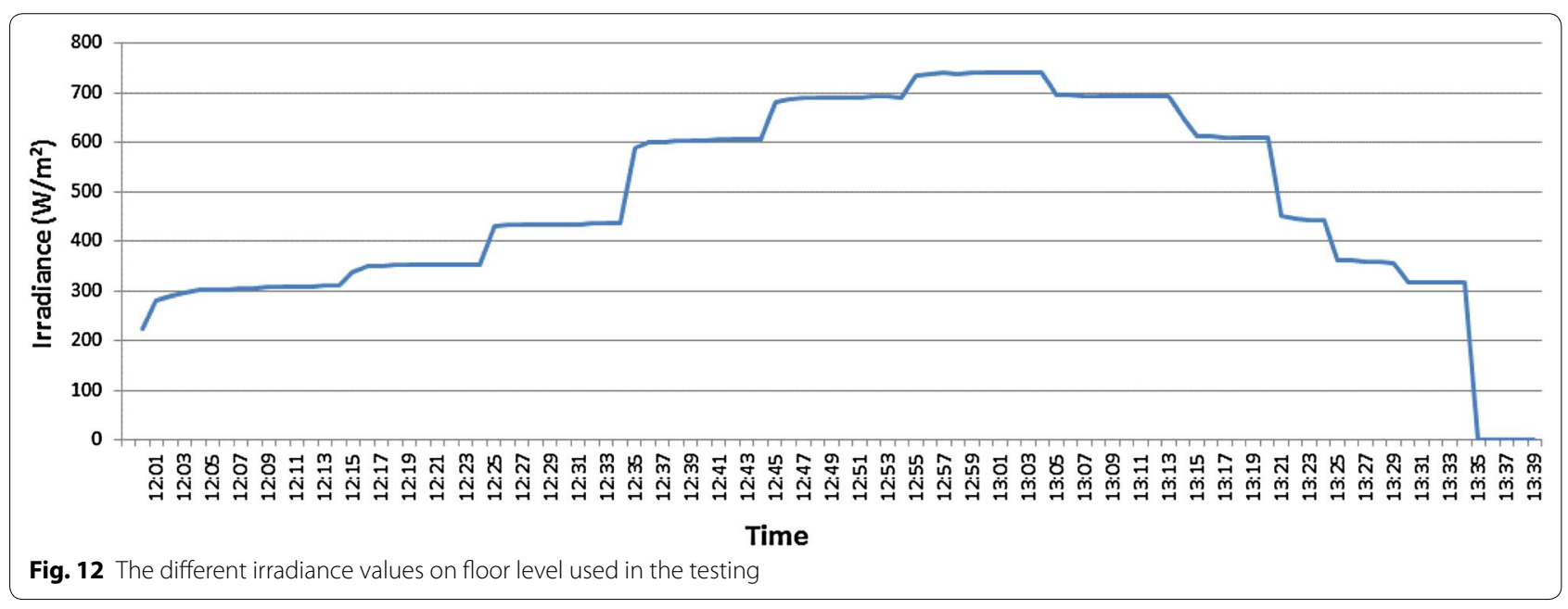


level the Normal PV produced more output than the PV with the split mirror see Fig. 13a. The power difference between the splitted spectrum PV and the full spectrum PV exceeded the $40 \%$ at low irradiance as shown in Fig. 13b. The PVs temperatures during the test are shown in Fig. 14, which clearly shows that the split spectrum PV was cooler than the full spectrum PV at all times.

The performance comparison of the hybrid system (PV + TEG) and the Normal PV only system provided clear information on the difference in power that can be produced if the full spectrum of the sunlight is harnessed as shown in Fig. 15. The advantage of the power output of the hybrid system varied with the irradiance levels due to the factors mentioned above as well as the temperature difference between the TEG surfaces. The TEG power output is slightly better at higher irradiance levels; an average of around $10 \%$ of the PV power output throughout the test with a constant ambient temperature of $50{ }^{\circ} \mathrm{C}$. The efficiency curve of the TEG as calculated from the equations stated above along with information from

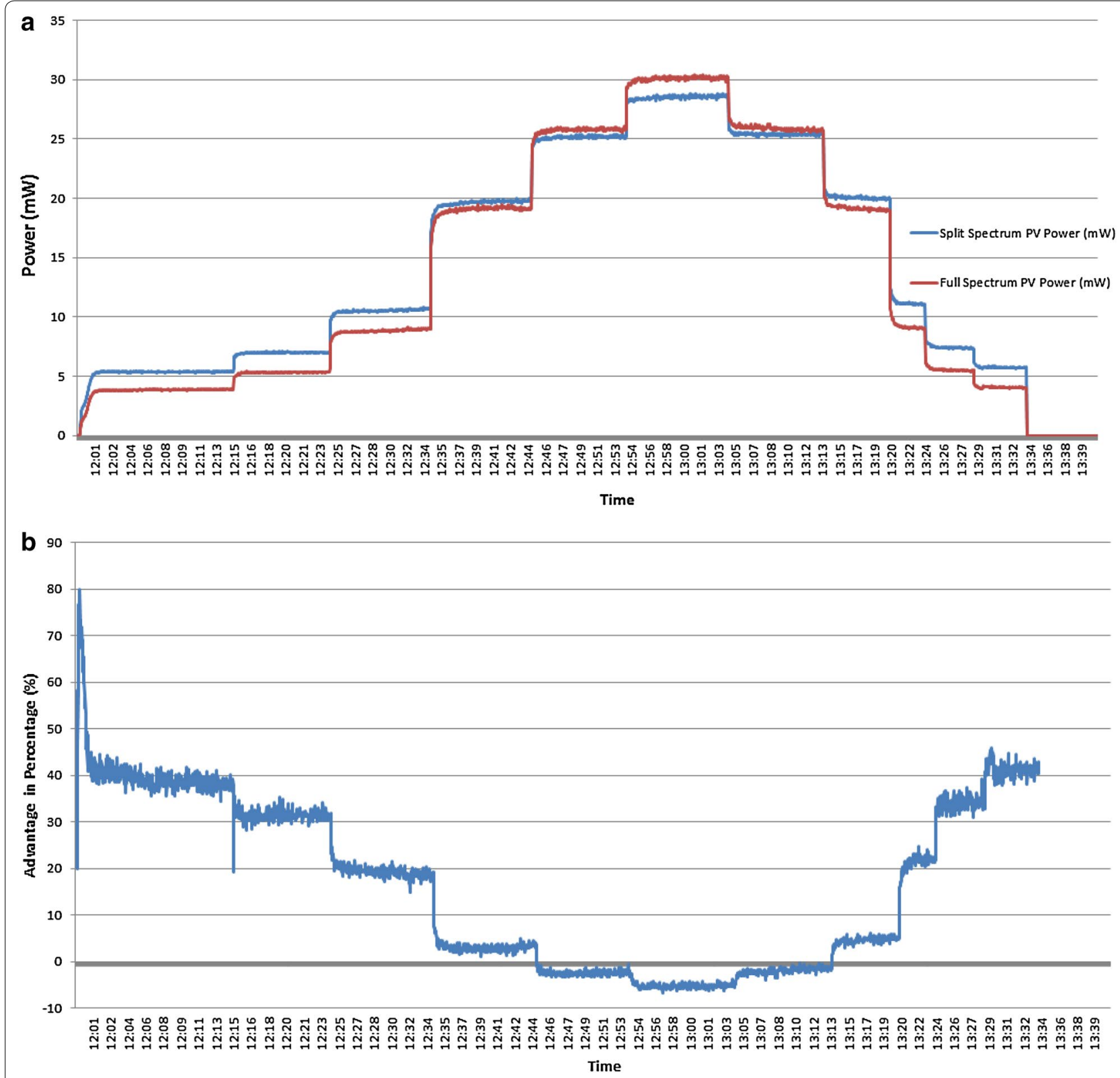

Fig. 13 Comparison of the power outputs of the PV panels only, in the normal (full spectrum) and hybrid (split spectrum) systems: a PV power outputs; $\mathbf{b}$ performance difference in percentage 

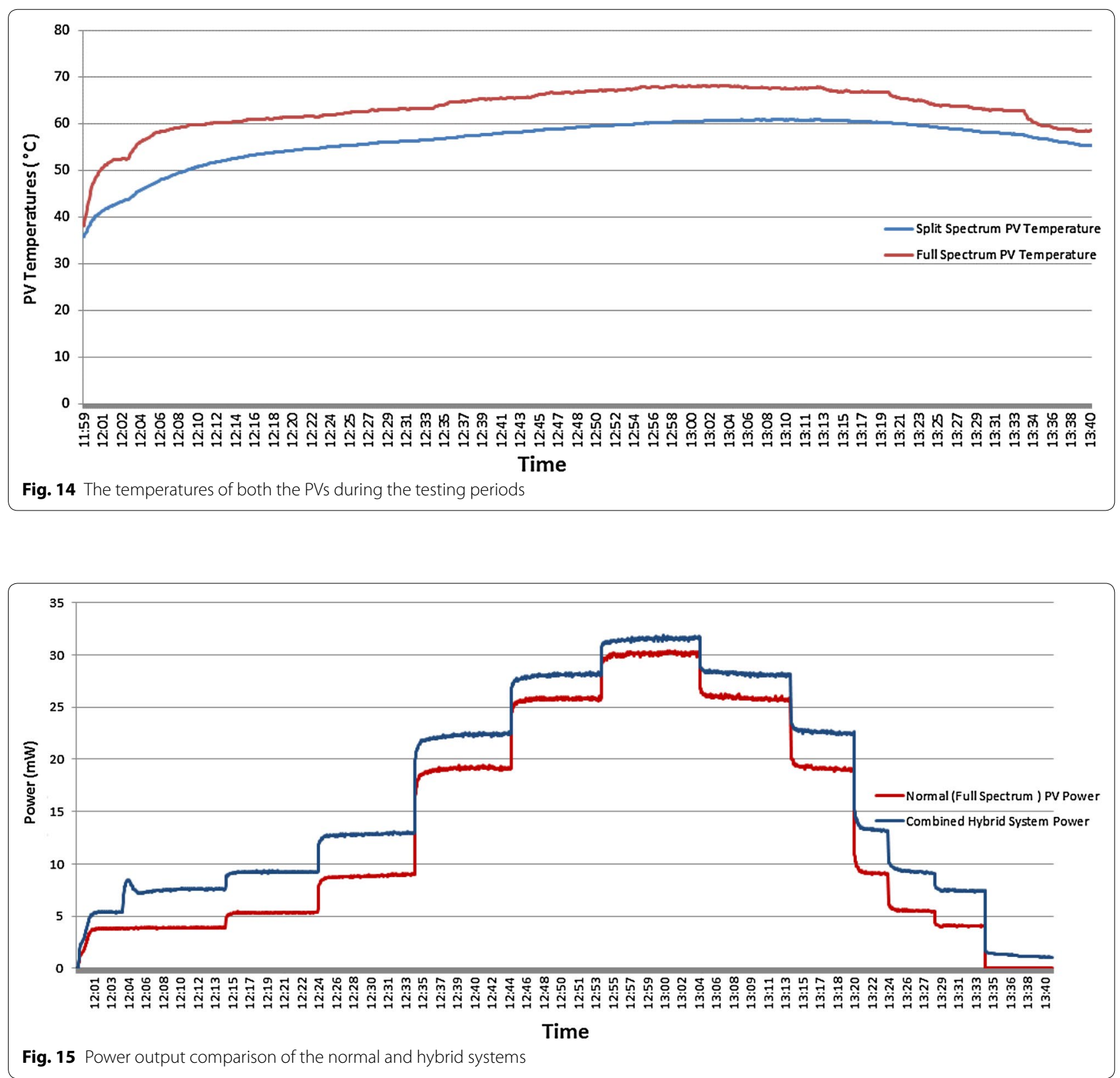

the tests (Product Page: Hi-Z 2015) is provided in Fig. 16. The low TEG module efficiency is due to the lower temperature and heat absorbed by the TEG.

The hybrid system (PV + TEG) performed better than the Normal PV throughout the test period and the maximum difference achieved was nearly double that of the Normal (full spectrum) PV as shown in Fig. 17. The difference between the power outputs increased at lower irradiance levels (nearly $80 \%$ difference at $300 \mathrm{~W} / \mathrm{m}^{2}$ ) however; the difference reduced as the irradiance levels increased, (nearly around $5 \%$ at $800 \mathrm{~W} / \mathrm{m}^{2}$ ) Further studies based on change of the ambient temperature (instead of using the same ambient temperature at all irradiance levels) can lead to further information for controlling or tuning the system performance. This data can also be used to predict the performance of the hybrid system at different ambient climate conditions.

\section{Conclusion}

This study investigated the performance of a photovoltaic (PV) and thermoelectric generator (TEG) assembly by changing its material constitution and design features. The TEG is anticipated to be integrated with PV modules to form a hybrid photovoltaic along with a sunbeam 

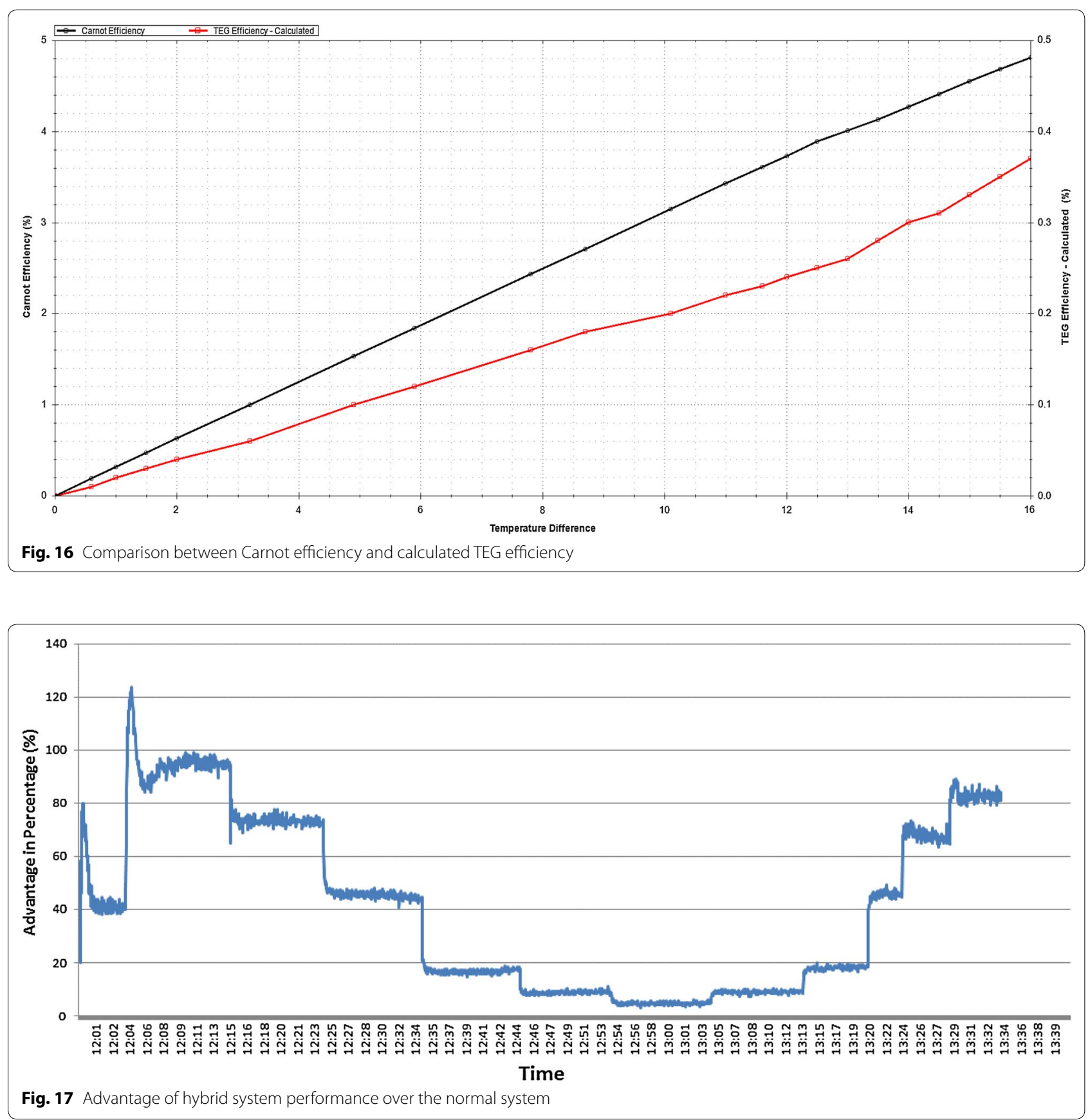

splitter to increase the overall conversion efficiency from solar irradiance to electricity.

The thermoelectric conversion efficiency is proportional to the temperature difference between the absorber's hot and cold surfaces; however, the PV efficiency reduces with the increase of its temperature. The methods used to enhance the hybrid system performance were proposed. Their corresponding experiments were performed and the initial results were presented.
Conclusively, proper selections of selective absorbance materials of the absorber are contributive to the thermoelectric generation. Alleviation of the convective heat loss from the surface of the absorber results in substantial positive impact to a TEG. The PV showed a better overall performance with the beam splitter. The proposed concepts and the positive experimental results provide useful information and reference for the further development of a hybrid PV-TE system for field testings. 


\section{Author details}

${ }^{1}$ Gulf Organisation for Research and Development, QSTP, Doha, Qatar.

${ }^{2}$ Department of Energy Systems, Fraunhofer IPM, Freiburg, Germany.

\section{Competing interests}

The authors would like to acknowledge the Qatar National Research Fund for funding the presented work in the NPRP: 5-363-069.

Received: 19 August 2015 Accepted: 23 October 2015

Published online: 04 November 2015

\section{References}

Baranowski, L. L., Snyder, G. J., \& Toberer, E. S. (2012). Concentrated solar thermoelectric generators. Energy and Environmental Science, 5(10), 9055-9067.

Chávez Urbiola, E., Vorobiev, Y. (2013). Investigation of solar hybrid electric/ thermal system with radiation concentrator and thermoelectric generator. International Journal of Photoenergy.

Datasheet: Cold Mirror. (2015). http://www.opticsbalzers.com. Accessed June 2015.

Datasheet: INA219 sensor. (2015). http://www.adafruit.com/datasheets/ina219. pdf. Accessed Sep 2015

Datasheet: LM35 sensor. (2015). http://www.ti.com/lit/ds/symlink/Im35.pdf. Accessed Sep 2015.

Datasheet: RTC. (2015). http://datasheets.maximintegrated.com/en/ds/ DS1307.pdf

Datasheet: Solare Absorberbeschichtungen. (2015). http://www.almecosolar. com. Accessed June 2015

Eswaramoorthy, M., \& Shanmugam, S. (2013). Energy sources, Part A: recovery, utilization, and environmental effects. Energy Sourc, 35, 487.

Jaegle, M., Bartel, M., Ebling, D., Jacquot, A., \& Böttner, H. (2008). Anisotropy and inhomogeneity measurement of the transport properties of spark plasma sintered thermoelectric materials, in European Thermoelectric Conference Paris.

Kalogirou, S. A. (2013). Solar thermoelectric power generation in cyprus: selection of the best system. Renewable Energy, 49, 278-281.

Kraemer, D., et al. (2011). High-performance flat-panel solar thermoelectric generators with high thermal concentration. Nature Materials, 10, 532.

Leon, M. T. D., Chong, H., \& Kraft, M. (2012). Procedia Engineering, 47, 76.

Lertsatitthanakorn, C., Jamradloedluk, J., \& Rungsiyopas, M. (2013a). Thermal modeling of a hybrid thermoelectric solar collector with a compound parabolic concentrator. Journal of Electronic Materials, 42, 2119.

Lertsatitthanakorn, C., Jamradloedluk, J., Rungsiyopas, M., Therdyothin, A., \& Soponronnarit, S. (2013b). Performance analysis of a thermoelectric solar collector integrated with a heat pump. Journal of Electronic Materials, 42, 2320
Lippong, T., Singh, B., Date, A., Akbarzadeh, A. (2012). 2012 IEEE International Conference in Power and Energy (PECon), p. 105.

McEnaney, K., Kraemer, D., Ren, Z. F., \& Chen, G. (2011). Modeling of concentrating solar thermoelectric generators. Journal of Applied Physics, 110, 6.

Meir, S., Stephanos, C., Geballe, T. H., \& Mannhart, J. (2013). Highly-efficient thermoelectronic conversion of solar energy and heat into electric power. Journal of Renewable and Sustainable Energy, 5, 043127.

Mizoshiri, M., Mikami, M., \& Ozaki, K. (2012). Thermal-photovoltaic hybrid solar generator using thin-film thermoelectric modules. Japanese Journal of Applied Physics, 51, 06 fl07.

Ogbonnaya, E., Gunasekaran, A., \& Weiss, L. (2013). Microsystem technologiesmicro-and nanosystems-information storage and processing systems, 19, 995.

Product Page: Aquaduct. (2015). http://shop.aquacomputer.de/product_info. php?products_id=3029. Accessed Sep 2015.

Product Page: Arctic Silver. (2015). http://www.arcticsilver.com/tc.htm. Accessed Sep 2015.

Product Page: Atlas SEC 1100. (2015). http://atlas-mts.com/products/productdetail/pid/242/. Accessed September 2015.

Product Page: Hi-Z 2. (2015). http://www.hi-Z.com/uploads/2/3/0/9/23090410/ hz-2.pdf.

Quick cool shop. (2015). http://www.quick-cool-shop.de/. Accessed Sep 2015.

Seebeck, T.J. (1895). Magnetische Polarisation der Metalle und Erze durch Temperaturdifferenz. W. Engelmann, Leipzig, Ostwalds Klassiker der exakten Wissenschaften $\mathrm{Nr} 70$

Tritt, T. M., Böttner, H., \& Chen, L. (2008). Thermoelectrics: direct solar thermal energy conversion. MRS Bulletin, 33, 366-368. doi:10.1557/mrs2008.73.

van Sark, W. (2011). Feasibility of photovoltaic-thermoelectric hybrid modules. Applied Energy, 88, 2785.

Wang, N., Han, L., He, H. C., Park, N. H., \& Koumoto, K. (2011). A high-performance spectrally-selective solar absorber based on a yttria-stabilized zirconia cermet with high-temperature stability. Energy and Environmental Science, 4, 3676

Website. (2015). www.acktar.com. Accessed June 2015

Weinstein, L. A., McEnaney, K., \& Chen, G. (2013). Modeling of thin-film solar thermoelectric generators. Journal of Applied Physics, 113, 164504.

Yang, Y., Zhang, H. L., Lin, Z. H., Liu, Y., Chen, J., Lin, Z. Y., et al. (2013). Energy and Environmental Science, 6, 2429

Zhang, M., Miao, L., Kang, Y. P., Tanemura, S., Fisher, C. A. J., Xu, G., et al. (2013). Efficient, low-cost solar thermoelectric cogenerators comprising evacuated tubular solar collectors and thermoelectric modules. Applied Energy, 109,51

\section{Submit your manuscript to a SpringerOpen ${ }^{\circ}$ journal and benefit from:}

- Convenient online submission

- Rigorous peer review

- Immediate publication on acceptance

- Open access: articles freely available online

- High visibility within the field

- Retaining the copyright to your article

Submit your next manuscript at springeropen.com 